\title{
Animal models of psychopathology: Historical models and the pavlovian contribution
}

\section{Modelos animales en psicopatología: Modelos históricos y la contribución pavloviana}

\author{
Mario A. Laborda \\ Department of Psychology, State University of New York - Binghamton, USA. \\ Departamento de Psicología, FACSO, Universidad de Chile, Chile. \\ Gonzalo Miguez \\ Department of Psychology, State University of New York - Binghamton, USA \\ Cody W. Polack \\ Department of Psychology, State University of New York - Binghamton, USA \\ $\&$ \\ Ralph R. Miller \\ Department of Psychology, State University of New York - Binghamton, USA
}

(Rec: 10 de diciembre de 2011 / Acep: 3 de enero de 2012)

\begin{abstract}
Resumen
La investigación con animales no humanos como sujetos experimentales, para entender el comportamiento humano, se basa en la noción darwiniana de la continuidad de las especies. En este marco encontramos modelos análogos para entender la biología y el comportamiento humanos en especies no humanas. En psicología, los modelos animales han probado ser una herramienta efectiva para el entendimiento del comportamiento humano, tanto normal como anormal. En la presente revisión discutimos cómo los modelos animales han sido usados al investigar la psicopatología. Luego de revisar tres modelos animales históricos de psicopatologías específicas, discutimos cómo los fenómenos descubiertos al estudiar el condicionamiento pavloviano han contribuido a nuestra comprensión de la etiología y mantención de la psicopatología humana, cómo la tradición pavloviana ha contribuido al desarrollo de mejores formas de tratamiento para desórdenes del comportamiento, y de forma más general, cómo los fenómenos pavlovianos se encuentran implicados en casi todas las interacciones entre un organismo y su ambiente.
\end{abstract}

Palabras clave: Condicionamiento pavloviano, modelos animales, psicopatología experimental.

\begin{abstract}
Research using non-human animals as experimental subjects to understand human behavior have been based on the Darwinian notion of continuity between species. In this framework, we find analogous models to understand human biology and behavior in nonhuman species. In the scientific study of psychology, animal models have proven to be an effective tool for understanding both normal and abnormal human behaviors. In the present review, we discuss how animal models have been used in investigating psychopathology. After reviewing three historical animal models of specific psychopathologies, we discuss how phenomena discovered while studying Pavlovian conditioning have contributed to our understanding of the etiology and maintenance of human psychopathology, how the Pavlovian tradition has contributed to the development of better ways to treat these behavioral disorders, and more generally, how Pavlovian phenomena are implicated in almost all interactions between an organism and its environment.

Keywords: Pavlovian conditioning, animal models, experimental psychopathology.
\end{abstract}

National Institute of Mental Health Grant 33881 supported this research. Mario Laborda was supported by the Comisión Nacional de Investigación Científica y Tecnológica (CONICYT-Chile). Gonzalo Miguez was supported by CONICYT-Chile and the Fulbright Program.

Correspondence: Ralph R. Miller, Department of Psychology, SUNY - Binghamton, Binghamton, NY 13902-6000, USA, Phone (607) 777-2291, Fax (607) 777-4890. E-mail: rmiller@binghamton.edu 


\section{Historical Models and the Pavlovian Contribution}

"... I believe that an understanding of other species and of simple processes is relevant to the understanding of complex processes in man. More than relevant-essential..." (Seligman, 1975, p. X) In this review we present arguments in line with this sentiment expressed by Seligman when introducing his book on learned helplessness, which provides a widely cited animal model of depression. Animal research has been part and parcel since the very beginnings of the scientific study of psychology, and it has been of pivotal importance when searching for basic determinants of the behavior of all organisms, including humans (Pavlov, 1927; Skinner, 1938; Thorndike, 1911).

As Domjan (2010, pp. 25-26) has proposed, the use of animals in psychological research is useful because: a) working with animals allows better control of the influences of both genes and past experience in present-day behavior than does working directly with humans, b) animal studies permit us to evaluate how maladaptive behaviors are acquired (studying humans is constrained to preexisting conditions), c) studying animal behavior allows researchers to evaluate the evolution and the neurobiological bases of learning, and d) animals do not try to please or displease the experimenter, as humans do, and e) animal behavior is not complicated by complex linguistic processes.

In addition to these reasons, we think that an important motivation for using non-human analogues to study human psychopathology rests in the fact that the most effective psychotherapeutic treatments available today were derived from basic principles discovered in the animal laboratory, which supports the effectiveness of translating results from the animal laboratory to clinical settings (e.g., Chambless \& Ollendick, 2001; Ortiz \& Vera-Villarroel, 2003; VeraVillarroel \& Mustaca, 2006). Consistent with this statement, Mustaca (2004) analyzed the treatments listed as empirically supported by Chambless and Ollendick (2001) and found that more than $88 \%$ of them can be classified as types of behavior or behavior-cognitive therapy (a percentage that increases to $96 \%$ when therapies with other theoretical frameworks, but that used behavioral techniques, were included), which are well-known for having direct roots in the animal learning laboratory. In our opinion, this result is not surprising considering that treatments based on basic research begin a step ahead of other types of treatments (given its solid foundations) when being evaluated in randomized clinical trials. In agreement with Mustaca and many others (e.g., Domjan \& Purdy, 1995; Laborda, 2009; Overmier, 2007), we assert that basic research in the animal laboratory must continue searching for the determinants of behavior, contributing to the understanding of human psychopathology and to the development of its treatment.
Unfortunately, the contributions of animal research to the understanding of normal and abnormal human behavior have not always been recognized. Domjan \& Purdy (1995) reviewed the most important introductory books to psychology and found that, even considering how successful the research with animals has been in the history of psychology, the authors uniformly did not explicitly recognize the vast contribution of this type of research to the current knowledge of human behavior. In fact, they often presented important results from animal research as having been achieved using humans as experimental participants. The only exception was in learning and conditioning texts, where the authors explicitly stated that most of the advances have been made through studying the behavior of non-human animals. In a similar tenet, Overmier (2007) considered surprising that, even after so many contributions of animal research to applied settings (e.g., systematic desensitization; Wolpe, 1958), most applied psychologists fail to recognize how much they owe to basic research with animals. As an example of how the benefits of animal research are widely ignored by applied psychologists, Overmier (2007) discussed part of the results of a recent questionnaire, "when they are asked if they use findings from animal research in their clinical practice, almost $90 \%$ have answered No. But when asked separately if they have use systematic desensitization in their practice, a huge percentage of them answer Yes" (p. 215). Considering that the development of the systematic desensitization technique has its roots in Wolpe's (1952) studies in relation to what is known as experimental neurosis in cats, the answers given by the polled psychologists evidenced an ignorance concerning the rationale beneath the techniques they often use in their professional activities.

But what is the basis of applying the results from animal research to humans? The Darwinian proposition that all organisms share a common ancestor (e.g., continuity of the species; Darwin, 1859), which suggests that basic neural and behavioral mechanisms are shared among different species, justifies the use of non-human animals when searching for determinants of human behavior. In line with his early proposal, Darwin (1872) himself initiated comparative studies when investigating emotional expression across species. The idea of humans being evolutionarily connected with all the other animals can be of great help when trying to understand who we are both biologically and behaviorally.

Interestingly, the usefulness of animal models in understanding physical illness (not to imply that behavioral disorders ultimately lack a material substrate), such as flu and cancer, and in developing cures for them is obvious, and few would disagree that these types of models are essential for high-quality medical research. In fact, few people would agree to be treated for any physical illness using techniques or medicines that had not been properly developed and tested (unless they are looking for alternative treatments when no scientifically validated treatment is 
available). Likewise, most people would reject any attempt of testing new treatments for physical illness using human participants if such treatments have not already been tested with successful and rigorous experimental trials using nonhuman animals. However, when applying the same logic to behavioral disorders, such as depression, phobias, and addictions, many people have trouble seeing animal models as a significant scientific tool. This contrasts with the fact that in psychology only a minority of the numerous types of treatments available (at least 450 available types of treatments already in the 1980 s as iterated by Karasu, $1986)$ is based in results from such rigorous research (e.g., exposure therapy). This situation is worrisome, as stated by Overmier (2007); a psychology with no interest in the scientific study of behavior is like a medicine without concern for its physiological consequences.

In the present article an argument in favor of the use of animal research in the development of psychotherapy is presented. In the next section we review three historical animal models of psychopathology, and then the contributions of the study of Pavlovian learning to the understanding of the etiology, maintenance, treatment, relapse (and relapse prevention), and prevention of human psychopathology are examined.

\section{Three Historical Examples of Animal Models of Psychopathology}

Writing a comprehensive review of the existing animal models of psychopathology is virtually impossible due to the huge number of relevant experiments reported in the literature (see Overmier \& Burke, 1992). To our knowledge, no such review has been presented in the recent years. However, several partial/selective reviews of the literature concerning animal models of psychopathology have been published (e.g., Fernández, 2000; Kamenetzky \& Mustaca, 2004; Laborda, 2009; Meadows \& Zinbarg, 1991; Mineka, 1985; Mineka \& Zinbarg, 1991; Overmier, 2001, 2007; Zinbarg, 1990a; Zinbarg, 1990b; Zinbarg \& Mineka, 1991). Here we describe three of the clearest historical examples of animal models of psychopathology, selectively chosen from previous reviews and primary sources.

\section{Pavlov's Neurotic Dogs}

Pavlov (1927) and his colleagues (e.g., ShengerKrestinikova, 1921 cited in Pavlov, 1927) were pioneers in the experimental study of psychopathology using nonhuman animals as experimental subjects. Among other issues, they were interested in evaluating whether neurotic behavior could be experimentally induced in animals so its determinants could be studied and therapeutic approaches developed. Pavlov's animal model of neurotic behavior was denoted 'experimental neurosis'. In Shenger-Krestinikova's experiment, a dog received training in which powdered food was delivered every time a visual stimulus (a circle) was projected on to a screen. The animal promptly began salivating to the presentation of the circle. After conditioned responding to the circle was robust, a stimulus discrimination task began. In this phase the animal kept receiving food each time the circle was presented and, in addition, nonreinforced trials of a second stimulus (an ellipse with a ratio of the semi-axes 2:1) were included. The dog readily learned this simple discrimination, which was evidenced when comparing the amount of saliva secreted in the presence of the reinforced stimulus (the circle) relative to the nonreinforced cue (the ellipse). In a third and final experimental phase, the animal received discriminative training between the circle and ellipses that gradually approached a $1: 1$ semi-axes ratio (i.e., a circle). The animal managed to discriminate the circle from ellipses with $2: 1,3: 2$, and $4: 3$ semi-axes ratios; however, the animal failed to discriminate between the circle and an ellipse with a 9:8 semi-axes ratio (i.e., a very difficult discrimination). Moreover, what was once a quiet dog began eliciting emotional responses indicative of distress (i.e., aggressive and erratic behaviors). In Pavlov's words:

The hitherto quiet dog began to squeal in its stand, kept wriggling about, tore off with its teeth the apparatus for mechanical stimulation of the skin, and bit through the tubes connecting the animal's room with the observer, a behaviour which never happened before. On being taken into the experimental room the dog now barked violently, which was also contrary to its usual custom; in short it presented all the symptoms of a condition of acute neurosis (p. 291).

Krasnogorsky (1925, extended Pavlov's (1927) studies of neurotic dogs, this time with children as experimental participants. His studies commenced at the beginning of the nineteen hundreds, anticipating Watson and Rayner's (1920) study of fear conditioning in infants. Measuring the motor reflex of the opening of the mouth to food delivery, Krasnogorsky found that a 6-year-old child could easily master an auditory discrimination between 92 and 144 beats per minute (bpm), between 108 and $144 \mathrm{bpm}$, and between 120 and $144 \mathrm{bpm}$ (all produced by metronomes), when all presentations of the $144 \mathrm{bpm}$ were followed by food and the presentations of the other cues were not. However, after the discrimination between 120 vs. 144 bpm, the child began showing signs of distress. In Krasnogorsky's words: “... we observed an important change in the behavior of the child; having always been easy to deal with and quiet during the experiments, he now became irritable and refused to go to the laboratory" (p. 757). In fact, when the child was trained to set apart 132 from $144 \mathrm{bpm}$, the experiment needed to be discontinued because the child began crying often and was aggressive with peers. Also, the child stopped showing discriminatory behaviors learned earlier in the experiment. 
Krasnogorsky's description of his participant's behavior and Pavlov's description of his dog's behavior after difficult discriminations are strikingly similar. Pavlov's interest in psychopathology did not stop at producing experimental neuroses, he and his students also tried to treat neurotic dogs (experiments by Petrova, in Pavlov, 1927) and children (experiments by Krasnogorsky, 1925) with bromide (i.e., a sedative). Unfortunately, the treatment was mostly ineffective in releasing subjects from the symptoms of experimentally induced neurosis (Plaud, 2003).

An analysis by Mineka and Kihlstrom (1978) indicates that the procedures for creating experimental neurosis (e.g., Anderson \& Liddell, 1935; Gantt, 1944; Masserman, 1943; Pavlov, 1927; Wolpe, 1952) all share a common determinant: the infringement of the outcome's predictability and controllability. Thus, when "environmental events of vital importance to the organism become unpredictable, uncontrollable, or both" (Mineka \& Kihlstrom, 1978, p. 257), similar symptoms were displayed by subjects in all studies of experimental neurosis regardless of species (i.e., an adaptive behavior was lost and an atypical behavior emerged).

Pavlov's studies on experimental neurosis are important not only because of their specific results, but because they illustrated a way in which human psychopathology could be studied with high experimental control in the animal laboratory. Furthermore, Pavlov's research on experimental neurosis highlighted the role of "environmentally-based conditioning procedures in producing and eliminating neurotic behavior patterns" (Plaud, 2003, p.149), thereby providing theoretical foundations for an incipient behavior therapy, today's most frequently employed psychotherapeutic approach, and the clinical method with by far the most empirical support. For example, Wolpe's (1952, 1954, 1958) experimental, theoretical, and clinical work is a direct descendent of Pavlov's tradition.

\section{Wolpe's Anxious Cats}

Wolpe $(1952,1958)$ developed an animal model of the etiology of anxiety disorders and a treatment to cure them based on basic results found in the animal laboratory. In the basic preparation, cats received a few electric shocks in an experimental chamber immediately after an auditory cue was presented. The animals responded to the shock with fear responses (e.g., crouching, trembling, howling, etc.), that later become controlled by the auditory stimulus and generalized to the whole experimental cage. Of importance, Wolpe $(1952,1954)$ reported that nonreinforced exposure to the training context (i.e., extinction treatment) was ineffective in reducing these fear responses, even when the exposure was prolonged; however, this manipulation has been reported to be effective in decreasing fear and reducing subsequent recovery of fear responses in rats (e.g., Denniston, Chang \& Miller, 2003; Laborda \& Miller, 2012) and in treating patients with posttraumatic stress disorder
(Powers, Halpern, Ferenschak, Gillihan, \& Foa, 2010), among others. Likely, Wolpe's failure to find an effect of extinction treatment alone depended of his specific preparation and parameters.

Given that exposure alone was found to be ineffective in treating Wolpe's anxious cats, Wolpe (1952; see also Jones, 1924) evaluated whether conjoint exposure to the feared experimental chamber and the elicitation of a response contrary to anxiety (i.e., counterconditioning) was more effective in decreasing conditioned fear than exposure alone (i.e., extinction). After depriving fearful cats of food for 48 or 72 hours, he fed them in the fearinducing situation (Wolpe, 1954). Some of the cats ate and were cured, but others did not eat and were not cured. For those reluctant subjects, a more gradual approach was used. These animals were gradually exposed to, and fed in, fear-inducing situations, beginning with the less frightening ones (i.e., adjacent rooms that resembled the experimental room), and finishing in the training context (i.e., the most fear-inducing situation). After the cats stopped exhibiting anxiety to the experimental situation, they were still afraid of the auditory cue that had initially been paired with the shocks. To decrease this fear, a similar approach was used. The animals were fed at a certain distance from the continuously sounding auditory cue, and then gradually food was delivered closer and closer to the locus of the sound, until the animals eventually stopped presenting signs of anxiety to the auditory cue. Wolpe suggested that the same technique that decreased fear reactions in non-human animals could also cure anxious patients. However, to be historically fair, it was Mary Cover Jones (1924) who, many years earlier, and under the advice of John B. Watson, firstly treated fear in kids by pairing appetitive stimuli (i.e., food) with the feared object (a therapeutic approach denoted 'method of direct conditioning' by Jones). In spite of not been the first to apply this basic principle to clinical situations, it was Wolpe $(1954,1958)$ who delineated and publicized the basic steps or phases in treating an anxious patient using this type of technique.

In recent years, the study of counterconditioning has been expanded and its benefits qualified. Bouton and colleagues (e.g., Bouton \& Peck, 1992; Brooks, Hale, Nelson, \& Bouton, 1995; Peck \& Bouton, 1990) have found that after counterconditioning a fear reaction in rats, the original fear association is kept intact and it is expressed when the subject is removed from the circumstances (e.g., context) of counterconditioning treatment. More specifically, testing outside the context of counterconditioning (renewal; Peck $\&$ Bouton), after a delay following treatment (spontaneous recovery; Bouton \& Peck), or after a few unsignaled shocks in the test context (reinstatement; Brooks et al.) have been seen to reestablish responding indicative of the original association. These results closely parallel results from the extinction literature (Bouton, 1993), and suggest that, as 
with extinction, counterconditioning an association does not destroy the originally learned information.

Recently, Van Gucht, Baeyens, Vansteenwegen, Hermans \& Beckers (2010) found that counterconditioning of humans was more effective in decreasing cue-induced cravings and cue-elicited consumption of chocolate than mere extinction, extending the possible use of Wolpe's (1952) initial findings to feeding-related disorders, and perhaps even to the treatment of addictive behaviors. Along more applied lines of research, treatments based on counterconditioning have proven to help in pediatric rehabilitation settings (diminishing negative reactions to medical stimuli, Slifer, Eischen \& Busby, 2002), to alleviate chronic posttraumatic stress disorder (Paunovic, 2002, 2003), to diminish dental injection phobia (Coldwell et al., 2007), and to treat arachnophobia (de Jong, Vorage \& van den Hout, 2000), among other favorable results.

Wolpe's research is a prime example of how to translate basic research with animals to clinical application. His pioneering work has been fundamental for the development of many exposure-based approaches to behavioral disorders (e.g., García-García, Rosa-Alcázar \& Olivares-Olivares, 2011; Pérez-Acosta, 2005; Richard \& Lauterbach, 2006), despite more recent findings that suggest that mere exposure (i.e., extinction) is the major agent of change in exposure therapies (Carey, 2011), and not reciprocal inhibition as initially suggested by Wolpe $(1954,1995)$.

\section{Overmier, Maier, and Seligman's Helpless Dogs}

The inclusion of the concepts of unpredictability and uncontrollability as potential causes of distress and psychopathology has improved our understanding of many behavioral disorders (Mineka \& Kihlstrom, 1978). Of central importance here, unpredictability and uncontrollability are crucial concepts for one of the most studied animal models of depression, so-called learned helplessness (e.g., Overmier \& Seligman, 1967; Seligman, 1975; Seligman \& Maier, 1967).

Overmier and Seligman (1967) evaluated possible determinants of the interference produced by inescapable shocks in the subsequent acquisition of escape and avoidance responses (e.g., Leaf, 1964; Overmier \& Leaf, 1965). They trained dogs in four different conditions. In phase 1 , the control group did not receive unsignaled inescapable shocks, while three experimental sets of dogs received different numbers of unsignaled inescapable shocks of different intensities and densities. In phase 2, all dogs were trained to escape and avoid signaled shocks in a two-way shuttle box. Their results showed that those dogs that experienced unsignaled and inescapable shocks were slower in learning escape/avoidance behaviors than dogs without that prior treatment, independently of the number of shocks received, their intensity, or density. In addition, failures to escape in phase 2 were common in the groups trained with inescapable shocks, but not in the control condition. Overmier and Seligman hypothesized that helplessness is learned when an organism is taught that its responses are not effective in controlling aversive consequences.

Furthermore, Seligman and Maier (1967) evaluated whether uncontrollability over aversive experiences was a causal factor in learned helplessness. They compared the escape and avoidance performance of three groups of dogs in the shuttle box. Dogs in Group Escape received escape/ avoidance pretraining in a movement-restricting harness; dogs in Group Yoked received the same frequency, duration, and intensity of shocks while in the restrictive harness, but without the opportunity to escape or avoid the shocks (i.e., they received uncontrollable shocks), and finally, dogs in Group Normal did not receive any pretraining. Dogs in Group Normal learned to escape and avoid aversive stimulation in the shuttle box rapidly and with only a few errors. Critically, dogs that received a pretraining phase in which they had experience controlling aversive stimulation (i.e., Group Escape) did not show behaviors indicative of learned helplessness, whereas the Yoked group displayed learned helplessness (i.e., large latencies in escaping and many failures to escape the shock). Considering that Groups Yoked and Escape received equivalent aversive stimulation (these groups differed only in that dogs in the Escape group learned to terminate shocks and dogs in the Yoked group did not), it is likely that the experienced uncontrollability in the pretraining phase, and not the aversive experience itself, was causal in producing learned helplessness.

Seligman and Maier (1967) also asked whether pretraining with escapable shocks in the shuttle box prevents the usual detrimental effects of inescapable shocks in the harness. Performance of dogs that received pretraining with signaled and controllable shocks in the shuttle box before receiving uncontrollable and unsignaled shocks in the harness paralleled the behavior of those dogs that never received inescapable shocks, and contrasted with the behavior of dogs that did not receive escape pretraining prior to inescapable shocks. These and other results (e.g., Seligman, Maier, \& Solomon, 1971) prompted Seligman (1975) to propose the learned helplessness hypothesis. Put simply, this hypothesis maintains that, when animals receive inescapable shocks, they learn that their behavior is independent of the consequences they receive.

Accordingly with Seligman (1975), helpless organisms have a motivational deficit, evidenced by a lack of effort to act in the world, an associative deficit, evidenced by retarded acquisition of new contingencies between responses and consequences, and an emotional deficit, evidenced by apathy and other signs of distress. Of interest, many of the behavioral results of learned helplessness experiments in non-human animals parallel the behavior of clinically depressed humans (LoLordo, 2001). Seligman noticed that people with reactive depression find it more demanding to 
initiate simple tasks (i.e., a motivational deficit), they do not see their behavior as causal of the consequences they receive (i.e., an associative deficit), their physiological and emotional status changes (i.e., an emotional deficit), and also, as occurs with learned helplessness, (reactive) depression vanishes with time (more so the motivational and affective deficits than the associative deficit). Centrally, these similarities prompted Seligman to propose uncontrollability as the main etiological factor in (at least some types of) depression. For him, depressive people suffer from motivational, associative, and emotional deficits caused by confronting one or many uncontrollable situations (e.g., death of a loved one), very much as his dogs had experienced in his laboratory. Even though Seligman's initial theory and model of depression has been revised (e.g., Abramson, Metalsky, \& Alloy, 1989; Abramson, Seligman, \& Teasdale, 1978; see also Huesmann, 1978) to include cognitive aspects of human psychopathology (e.g., attributions about lack of control), its contribution to the understanding of depressive mood disorders is unquestionable.

In search for applications, Seligman, Maier, and Geer (1968) tested whether teaching dogs previously rendered helpless that their behavior can actually influence the aversive consequences they receive and can decrease the deficits provoked by prior uncontrollable aversive stimulation. Specifically, the authors treated dogs that chronically failed to escape shocks in the shuttle box after receiving uncontrollable shocks in the training harness. The treatment consisted of shaping the escape/avoidance behavior in helpless dogs, first eliminating the barrier that dogs have to cross to avoid the shocks in the shuttle box and calling them from the other side, and then later, forcing the dogs that did not learn to escape/avoid under the first manipulation by physically dragging them to the safe side of the box when appropriate. After these manipulations, all dogs showed good escape and avoidance behavior, even when the barrier was back in position, and this outcome was evident even after a period of time, suggesting enduring effects of the treatment. Electroconvulsive shocks (Dorworth \& Overmier, 1977) and select drugs (e.g., desmethylimipramine; Leshner, Remler, Biegon, \& Samuel, 1979) have also been shown to disrupt the interference produced by uncontrollable shock. Of translational importance, releasing learned helplessness animals from their deficits has been widely used as a criterion for testing the efficacy of anti-depressive drugs (e.g., Reed, Happe, Petty, \& Bylund, 2008; Reed et al., 2009; Valentine, Dow, Banasr, Pittman, \& Duman, 2008).

Neurotic dogs, anxious cats, and helpless dogs have been instructive models of human behavioral disorders and, if we have any success treating human patients in our clinics today, it is in large part due to the use of animals as experimental subjects in basic and applied research. Next we concisely present a modern view of Pavlovian conditioning for later discussion concerning specific roles that this type of learning plays in the acquisition, maintenance, and treatment of human psychopathologies.

\section{Beyond the Drooling Dog: The Pavlovian Contri- bution to Experimental Psychopathology}

No matter how perfect a bird's wing may be, it could never make the bird air-borne without the support of the air. Facts are the air of the scientist. Without them you will never be able to take off, without them your 'theories' will be barren. But when studying, experimenting and observing, do your best to get beneath the skin of the facts. Do not become hoarders of the facts. Try to penetrate into the secrets of their origin. Search persistently for the laws governing them (Pavlov, 1955, p. 52).

These words, originally written by Pavlov as part of a letter to motivate communist scientific youth, have inspired researchers for decades, and represent the spirit, the essence of the scientific study of animal behavior, and especially, much of the rationale for studying animal learning and cognition. For many years now, scientists from the Pavlovian tradition have been trying to find the principles beneath the behavioral phenomena we observe. Thanks to these efforts, today we have many empirically-based theories and models that propose different mechanisms governing the behavior of the organisms (e.g., Mackintosh, 1975; Pearce, 1987; Pearce \& Hall, 1980; Rescorla \& Wagner, 1972; Stout \& Miller, 2007; Wagner, 2003). Of special interest for the present review, the search for these mechanisms has produced many experimental preparations for the study of Pavlovian associations. As a product of this enterprise, a significant number of new associative phenomena have been discovered. Here we argue that these associative phenomena are not only important for the theoretical understanding of associative learning, but also because they model selected components of psychopathological behaviors and their treatment.

Learning principles discovered in the animal laboratory apply to many experiences that non-human animals have with their environment, and they have also been proposed to apply to normal and abnormal human behavior (e.g., Levis, 1991). In our view, there is not a principled reason to think that most basic phenomena discovered in the animal laboratory do not apply to analogous circumstances in humans.

In recent years, specific associative theories have been proposed as models of specific human disorders (e.g., Bouton, Mineka \& Barlow, 2001). However, to our knowledge, a detailed analysis of Pavlovian phenomena and their potential relationships to psychopathology in terms of modeling the etiology, maintenance, treatment, relapse, relapse prevention, and prevention of behavioral disorders, 
has not yet been formally presented. Here we propose such a perspective not with the intention of been exhaustive, but trying to illustrate how Pavlovian phenomena can be involved in many interactions between an organism and its environment, which includes the development and treatment of psychopathology. In the literature one can find many types of animal models of psychopathology, from impressive models (e.g., learned helplessness) that present similarities with a behavioral disorder (e.g., depression) in terms of symptoms, etiology, treatment, and even prevention, to models (so-called mini models) that are useful in studying just a few aspects of a given disorder (Mineka, 1985; Mineka \& Zinbarg, 1991). Most of the phenomena we discuss later belong to the latter category; however, we can think of a given Pavlovian preparation (e.g., fear conditioning) as a more inclusive model for a particular disorder (e.g., specific phobia).

The Pavlovian literature embraces a number of phenomena that could be viewed as having a role in many aspects of selected psychopathologies and their treatments. Some of these phenomena represent well-know models (e.g., extinction modeling exposure therapy); others are suggested here for the first time (e.g., recovery from blocking and overshadowing as a model of fear emergence). Before describing how Pavlovian phenomena model select psychopathologies, we briefly delineate the current status of the study of Pavlovian associations.

The contemporary status of the study of Pavlovian conditioning is far more complex and richer than a half century ago, and sadly, is largely misunderstood in today's mainstream psychology. Many years ago, when Yerkes \& Morgulis (1909) presented some of the early results from Pavlov's laboratory, the "salivary reflex method" (p. 257) was a simple quantitative strategy to measure changes in the salivary reflex produced by 'psychic processes' in the central nervous system. Pavlov (1927) noticed that the salivary reflex in his dogs was elicited under two very distinct circumstances, in the presence of a specific stimulus for secretion (e.g., food in the mouth; which he labeled unconditioned stimulus [US]), and when the animal was stimulated by events that were previously presented in connection with the US (e.g., lights, sounds, odors; which he labeled conditioned stimulus [CS]). Importantly, some years later Cason (1925) commenced to conceive Pavlovian conditioning as a much broader type of learning, one more closely related to the British empiricists of the $18^{\text {th }}$ and $19^{\text {th }}$ centuries and their ideas about associations between events, than to the Russian physiologists. Since publication of the early reports from Pavlov's laboratory, conditioning has proven to apply to many more situations than merely salivary reflexes in dogs. For instance, up to the mid twenties, conditioning was used to train motor reflexes in human infants (Krasnogorski, 1925), the pupillary reaction in adult humans (Cason, 1922), the knee jerk in humans (Twitmyer,
1902/1974), the salivary response in adult humans (Lashley, 1916), the chewing response in snails (Thompson, 1917), and importantly, conditioning was proved also to be a factor in the acquisition of emotional syndromes such as fear in children (Watson \& Rayner, 1920).

From a much more cognitive perspective, Rescorla (1988) proposed that, contrary to then prevailing views concerning Pavlovian conditioning, organisms do not simply acquire associations among any contiguous stimuli; rather, organisms use basic associations as building bricks to construct a rich knowledge of their world. For him, contiguity between two events was neither necessary nor sufficient for conditioning. He stressed instead the role of the information that a stimulus provides concerning another stimulus as the principal factor that generates learning (e.g., Rescorla \& Wagner, 1972). As supporting evidence of the importance of information in associative learning, Rescorla (1988) argued that some cue competition phenomena, such as the blocking effect (Kamin, 1968), demonstrated that contiguity was not sufficient for learning to occur. In a blocking design, a target cue shows little behavioral control at test despite its having been presented in the presence of a US. Thus, despite good contiguity between the target cue and the US, the target cue shows limited behavioral control, which was initially interpreted as a failure to acquire an association because the low informative value of the blocked cue (i.e., the blocked cue is redundant given that the blocking stimulus already predicts the US). However, today other interpretations are available. For example, Blaisdell, Gunther, and Miller (1999) showed that lower responding to the blocked cue was largely a performance deficit. Critically, they demonstrated that, after extinction of the blocking cue, the blocked stimulus began displaying behavioral control (i.e., demonstrating that during training the so-called blocked cue acquired an association with the US that was just not been expressed).

There are some important results that, in setting biological boundaries to associative learning, have also enriched the way in which we regard conditioning (see Shettleworth, 1972, 1994). For example, Garcia and Koelling (1966) and Cook and Mineka (1990) reported evidence that contradict the common belief that any pair of stimuli, if presented contiguously, would readily become associated. Garcia and Koelling showed that in rats, gustatory stimuli (i.e., flavor cues) are easier to associate with sickness than with cutaneous pain, and that audiovisual stimulation is readily associated with cutaneous pain, but not with sickness. Cook and Mineka reported that selective associations were also formed during observational fear conditioning in monkeys. In their research, rhesus monkeys acquired fear to toy snakes, but not to artificial flowers, by observing videotapes in which other monkeys responded fearfully to them.

Along the same lines, other researchers have shown that genetic and learned predisposition limit what an organism 
can learn. Williams \& Williams' (1969) negative automaintenance is a good example of genetic predispositions in learning. In their experiments, pigeons kept responding (pecking a key light) to cues that signaled food reward in an autoshaping preparation, even when their responses now precluded them from being rewarded. It seems that after a key light has been paired with food, pigeons find it very difficult to stop responding to it, even when responding was not necessary for receiving reinforcement in the first place, and when responding is no longer contingent with reinforcement. Pecking signals for food seems to be highly prepared in pigeons. In the case of acquired predispositions concerning learning, Gwinn's (1949) vicious circle experiment (a.k.a. experimental masochism; Bower \& Hilgard, 1981) is a good laboratory example. In Gwinn's experiment, rats perseverate on responding to reinforcement contingencies no longer in force. After learning to respond one way in a first phase of training, animals find it very difficult to change their behavior when the contingencies have changed. Their initially learned behavior interferes with the animal encountering the appropriate response to the new contingencies of reinforcement. It seems like first learned contingencies are, at least in some cases, an obstacle for learning new contingencies.

Adding more complexity to our conception of Pavlovian associations, modern researchers have noticed that not only are punctate cues associated with USs when trained together, but also the contexts in which training occurs (loosely defined as the surroundings of training) play an important role (e.g., Balsam \& Tomie, 1985). For example, Urcelay and Miller (2010) have shown that contexts serve a dual role in Pavlovian conditioning; they can have a cuelike role, establishing direct associations with the US, but also a role modulating the association between another stimulus and the US (i.e., as a positive or negative occasion setter, OS; Holland, 1983; Miller \& Oberling, 1998). While the cue-like role of contexts is relatively transparent (the context in which a CS is paired with a US can also acquire an association with the US and come to control behavior), its role as an OS is more complex. When cues are not good predictors of the presence or absence of the US (i.e., when CSs receive ambiguous training concerning the US), other cues present during training, such as the context of training, can come to disambiguate whether the US will occur or not after the CS. In the literature, both punctate CSs and contexts are found to play this role, and they can do it in both a positive (i.e., the CS is reinforced only in the presence of the OS) and negative (i.e., the CS is reinforced only in the absence of the OS) manner (see Schmajuk \& Holland, 1998). The discovery of phenomena such as these examples of hierarchical associations exponentially increases the possible associative structures that can be formed in any given situation. The modern conceptualization of this type of learning considers basic associations between multiple representations, which occur within complex hierarchical relationships, permitting organisms to create an intricate and multifaceted representation of their environment.

A deeper analysis of the current status of Pavlovian learning exceeds the scope of the present article. The interested reader would find it informative to examine some relatively recent articles concerning this subject (e.g., Domjan; 2005; Hollis, 1997; Pearce \& Bouton, 2001; Rescorla, 2003; Wasserman \& Miller, 1997). Next we discuss several Pavlovian situations that model forms of psychopathology.

\section{Modeling the Etiology, Maintenance, Treatment, Relapse, Relapse Prevention, and Prevention of Psychopathology}

The study of Pavlovian conditioning, since it's very beginnings, has led to the discovery of numerous associative phenomena that gave shape to what the field of conditioning is today and illustrate under which circumstances associations are formed. Here we discuss some of these phenomena, first describing them succinctly, and then explaining how they could be of interest in applied situations. To make our points clearer, we usually turn to the experimental and clinical literature related to anxiety/fear and addictive behaviors/drug tolerance because of the many relevant studies in print. But there is no reason to avoid applying the same principles to model features of other behavioral disorders for which learning experiences are crucial (e.g., some sexual dysfunctions).

\section{Etiology and maintenance}

To clarify how Pavlovian conditioning can explain the etiology and maintenance of some behavioral disorders in which learning appears to be essential, let us take as an example the development of simple phobias. As described earlier, in a Pavlovian paradigm two events are contiguously paired: the CS (in the case of a phobia, e.g., an animal), which is neutral before training, and the US (in the case of a phobia, e.g., an aversive stimulus), which naturally elicits an unconditioned response (UR; in the case of a phobia, e.g., fear). After pairings of these stimuli, an association between them is formed and the once neutral stimulus begins evoking a conditioned response (CR). In a more naturalistic situation, Watson and Rayner's (1920) demonstrated that infants were susceptible to learning emotional reactions (in this case a fear reaction). In their experiment, Albert, an eleven-month old child, was trained by presenting a rat (i.e., the CS) followed of an aversive loud noise (i.e., the US). After a few pairings, Albert began displaying signs of fear in the presence of the rat, which initially did not provoke such a reaction. After these results, Watson and Rayner suggested "It is probable that many of the phobias in psychopathology are true conditioned emotional reactions. .." (p. 14). This basic associative model provides the 
groundwork for more modern associative accounts of the etiology of fear and anxiety disorders (which today include temperament factors, experiential factors, and evolutionary considerations; e.g., Mineka \& Sutton, 2006; Mineka \& Zinbarg, 2006).

Considering that Pavlovian associations have been identify as causal in selected psychopathologies (e.g., anxiety disorders, addictive behaviors) and that these associations have shown to be more complex than originally thought (Rescorla, 1988), the proper identification of the environmental cues that should be targeted during therapy becomes essential. Along these lines, some Pavlovian phenomena must be considered to clearly delineate the acquisition of, for example, fear and phobias. But first, what types of events enter into associations should be take in consideration. We previously stated that punctate cues and contexts play a role in Pavlovian conditioning, as simple cues and as OSs (e.g., Bouton, 2010; Miller \& Oberling, 1998; Urcelay \& Miller, 2010); however, there are many types of cues and contexts to consider. For example, stimuli commonly used in the laboratory are audiovisual cues and flavors, but interoceptive stimulation (e.g., pressure from a stomach balloon), verbal and semantic stimuli (e.g., words or sentences), natural features of a sexual partner, and small doses of a drug (see Cusato \& Domjan, 1998; McDonald \& Siegel, 2004; Razran, 1961), are among other possible cues. Also, given that cognitions can be conceptualized as internal behaviors, there are good arguments for proposing that associations do not need to be formed solely between actual events in our environment, but also between mental representations (e.g., Dwyer, 2003; Field, 2006). In terms of contexts, they can be the physical surroundings of the organisms, but also their emotional states, drug states, instructions in humans, temperature, deprivation states, and even time could constitute a context (for a review, see Bouton, 2010), among others.

Making the scene even more complicated, during training at least two types of associations could be formed. First, an association between the CS and US is formed (usually denoted as a stimulus-outcome [S-O] association); second, the CS could also become associated with the UR (which is denoted as a stimulus-response [S-R] association). Why is this important? Well, there is evidence that $\mathrm{S}-\mathrm{R}$ associations often persist even when $\mathrm{S}-\mathrm{O}$ associations have been eliminated through outcome devaluation manipulations, which could explain why some people have no recollection of the traumatic events that initially established their fears (see Laborda \& Miller, 2011; Rescorla, 1973). Importantly, S-R associations are also susceptible to extinction and recovery from extinction phenomena (Laborda \& Miller), so it is likely that the behavioral techniques proved to reduce recovery in S-O associations (see below) would also be effective in preventing recovery of extinguished S-R associations.
Now that we have introduced some of the complexity inherent to Pavlovian associations, we will review a few phenomena we think are important to consider concerning the acquisition of new associations that support psychopathology or the treatment of psychopathology. First, associations are not formed only between CSs and USs; other hierarchical associations are possible. For example, in a sensory preconditioning preparation two cues can become associated even when neither of them are biological significant. In this case, two CSs (CS2 and CS1) are initially paired, and then one of them (CS1) is paired with the US. As a result of this procedure, unsurprisingly CS1 acquires behavioral control and elicits a CR; however, CS2, which was never paired with the US, also acquires behavioral control and elicits a CR at test (Brogden, 1939; Rizley \& Rescorla, 1972). Another example is given by second-order conditioning. In this preparation, the phases of a sensory preconditioning experiment are reversed. First, CS1 is paired with the US, and then CS2 is associated with CS1. As a consequence of this training, CS2 also acquires behavioral control (e.g., Pavlov, 1927; Rescorla, 1973). A final example of hierarchical associations is seen in occasion setting phenomena. As described earlier, when CSs are ambiguous in predicting an outcome, other cues or contexts can come to disambiguate the situation. Occasion setting has been proved to be involved in many behavioral preparations (see Schmajuk \& Holland, 1998), and it plays a fundamental role in addictions and drug tolerance (e.g., Betancourt, Inostroza, \& Laborda, 2008; Ramos, Siegel \& Bueno, 2002). As suggested elsewhere (e.g., Mineka, 1985; Davey, 1992), these hierarchical associations should be kept in mind by clinicians because they increase the potential associations that can be responsible for the acquisition of some behavioral disorders.

An additional consideration, and one usually ignored in terms of clinical application, is the role that the so-called cue competition phenomena (e.g., overshadowing, blocking) can play in the emergence of latent associations. In an overshadowing preparation, two cues of different saliences are paired in compound with a US. As a consequence of the differential salience of the stimuli, the more salient cue (i.e., the overshadowing cue) elicits strong responding at test; however, the less salience cue (i.e., the overshadowed cue) does not (Pavlov, 1927). However, an overshadowed cue still acquires behavioral control; this control is just not being expressed unless the informative value of the overshadowing cue is devaluated (e.g., by extinguishing it; Matzel, Schachtman \& Miller, 1985). In applied terms, exposure to a given stimulus might make latent learning concerning other cues to be behaviorally expressed, eliciting the very same responses that treatment was trying to reduce but now to a different stimulus. In such cases, both stimuli are best extinguished. 
In summary, Pavlovian associations are complex and if taken lightly, can cause us to make serious mistakes in terms of application in psychotherapy. For instance, ignoring hierarchical associations and cues that have been overshadowed or blocked can lead us to fail in determining which situations should be targeted in treatment.

\section{Treatment}

Pavlov (1927) reported a decrease in responding to an excitatory CS is a product of nonreinforced presentations of the CS after acquisition training. This phenomena, know as experimental extinction, has been claimed as an associative model of exposure therapies (e.g., Bouton \& Nelson, 1998; Hofmann, 2008). In exposure therapy for a specific phobia, the feared object is considered a CS, which, when repeatedly presented without the aversive stimulus (i.e., the US), loses its potential to elicit fear responses. The same is true concerning cue exposure treatment for addictive behaviors. In this case, cues associated with drug intake, when extinguished, reduce the strength of the cravings they usually provoke (e.g., Collins \& Brandon, 2002; see also Drummond, Tiffany, Glautier, \& Remington, 1995). Unfortunately, as with exposure therapy, the success of extinction treatment in reducing conditioned responding has been challenged by many situations that show its effects are not necessarily easily achieved or long standing (i.e., recovery from extinction in the laboratory and relapse after exposure therapy in clinical settings are common). In the following section, we discuss some of these associative phenomena (e.g., resistance to extinction treatment, renewal, reinstatement, and spontaneous recovery).

Given the complexity of many Pavlovian structures, some precautions should be taken to produce truly effective and enduring extinction. First, the existence of hierarchical associations should be assessed. Positive and negative OSs have proved not to be affected by conventional extinction treatments. Instead, to extinguish an OS the whole sequence of events have to be presented, this time with the reinforcement contingency reversed (i.e., for positive occasion setting, OS $\rightarrow \mathrm{CS} \rightarrow$ NoUS; see Rescorla, 1986). In regard to sensory preconditioning and second-order associations, it has been shown that extinguishing the CS that was paired with the US (i.e., CS1) does not necessarily decrease responding to the secondarily associated CSs, probably because both CS2-R and CS2-O associations as well as CS1-O are formed in these preparations (Rescorla, 1973; Rizley \& Rescorla, 1972). Similarly, extinction of blocking and overshadowing cues has been shown to allow blocked and overshadowed cues to express behavioral control, which was presumably latent prior to extinction (e.g., Blaisdell et al., 1999; Matzel et al., 1985). In summary, proper identification of the associative structure involved in a given learning situation is crucial for producing robust extinction without encouraging responding to some other CS.

\section{Relapse}

Unfortunately, the long-term effects of extinction are often not enduring, as indicated by several associative phenomena that model relapse from exposure therapy. For example, a few presentations of the US after extinction often induce partial recovery of the extinguished CR (reinstatement; e.g., Norambuena, Quintana, Ponce \& Vogel, 2010; Rescorla \& Heth, 1975). In practical terms, even brief traumatic events could make a 'recovered' patient relapse, even if the experience is not paired with the feared stimulus. Similarly, training an extinguished stimulus is usually faster than training a new stimulus (rapid reacquisition; e.g., Pavlov, 1927). In applied terms, a 'cured' patient reacquires his abnormal behavior faster than he initially acquired it. Along similar lines, changes in the temporal (spontaneous recovery; e.g., Pavlov, 1927) and physical context (renewal; e.g., Bouton \& Bolles, 1979; Laborda, Witnauer \& Miller, 2011) from that of extinction provoke partial recovery of the extinguished CR. Importantly, these context shift effects in experimental extinction also occur after exposure therapy. In a clinical setting, relapse often occurs in a situation outside the therapeutic setting and after an appreciable period of time since treatment. Importantly, recent experiments suggest that recovery from extinction due to a physical context shift (i.e., renewal) and to the introduction of a long delay between extinction and testing (i.e., spontaneous recovery) summate producing a stronger recovery of the extinguished conditioned response than either of these recovery-from-extinction phenomena alone (Laborda \& Miller, 2012; Rosas \& Bouton, 1998).

\section{Relapse prevention}

In search of producing extinction free of recovery, recent research concerning experimental extinction has identified some behavioral techniques to attenuate the recovery of extinguished conditioned responses (see Laborda, McConnell \& Miller, 2011; Miller \& Laborda, 2011). If experimental extinction models exposure therapy, and renewal and other recovery-from-extinction situations model relapse after exposure therapy, then the techniques that reduce recovery from extinction could also be used to model a reduction in relapse. We present here some of these techniques.

Denniston et al., (2003) evaluated whether augmenting the number of extinction trials would attenuate renewal, using rats as subjects in a conditioned lick suppression paradigm (a manipulation that arguably strengthens the extinction memory; Laborda \& Miller, in press). After CS-US pairings (i.e., white noisefootshock pairings) in one context, subjects received a moderate or a massive number of extinction trials in a second context. At test for responding to the CS in a neutral context and in the acquisition context 
(two different locations in which renewal would be expected), subjects with extensive extinction treatment showed less renewal of the extinguished responses than subjects with moderate extinction treatment.

In another example, Gunther, Denniston \& Miller (1998) evaluated the possibility of extinction treatment in multiple contexts attenuating renewal, using rats as subjects in a conditioned lick suppression paradigm (a manipulation that arguably enhances contextual generalization; Laborda \& Miller, in press). After CS-US pairings (i.e., white noise-footshock pairings) in one context, subjects received extinction trials in one or three different contexts. Rats that received extinction treatment in multiple contexts showed less renewal in a neutral context than rats that received the same number of extinction trials in only one context. Moreover, Laborda \& Miller (2012) evaluated the conjoint effect of massive extinction and extinction in multiple contexts in reducing recovery of extinguished conditioned responses after a delayed context shift (in which renewal and spontaneous recovery summated). Their results indicate that the combination of these techniques attenuated this recovery more than either of these recovery-attenuating treatments alone. As can be seen from these examples, the systematic study of animal behavior in the Pavlovian laboratory can be truly informative when trying to develop better therapeutic techniques.

\section{Prevention}

Finally, it has been suggested that the CS-preexposure effect (a.k.a. latent inhibition; Lubow \& Moore, 1959) could be a good model for prevention in clinical settings (e.g., Lubow, 1998). In a typical CS-preexposure experiment, a CS is presented alone a large number of times before pairing it with the US. As a consequence of this preexposure procedure, the target CS, when paired later with the US, is retarded in acquiring behavior control, compared with a group that lacks of the preexposure manipulation. In clinical terms, for example, potential phobic objects (e.g., dogs), if preexposed, are less likely to be feared in the future if they become involved in a traumatic event (Bouton et al., 2001). In addictions, drinking or smoking related cues, if preexposed, should be less likely to be associated with drug consumption in the future (e.g., Goodison \& Siegel, 1995). Thus, appears that nonreinforced preexposure to a drug cue prior to conditioning results in a reduction in responding similar to nonreinforced postexposure of a CS (i.e., extinction). But, is this a permanent effect? As with extinction, it does not look like it is. For example, Wheeler, Chang and Miller (2003) showed that the CS-preexposure effect is reduced when testing occurs outside of the preexposure context, a phenomena similar to the renewal of extinguished CRs (for further parallels between CS preexposure and CS postexposure, see Laborda, Polack \& Miller, 2012). Interestingly, Wheeler et al. showed that preexposure in multiple contexts and massive preexposure (mirroring Gunther et al.'s, 1998, and Denniston et al.'s, 2003, manipulations to reduce recovery from extinction) prevent context-shift effects in CS preexposure.

As should be clear by this point, the Pavlovian contribution to the experimental study of psychopathology is multifaceted. This type of learning suggests how, when, and why associations are formed, maintained, and are expressed in the face of interference by opposing memories. Given the extensive support for this broad conception, we conclude that Pavlovian associations are causal in the development of some behavioral disorders, suggesting also ways to treat them.

\section{Final Remarks}

In the present review, we tried to develop the view that the use of animals in psychological research in not only necessary, but essential for the development of the discipline as a whole and for the clinical science in particular. Early on, Robert M. Yerkes stated that "Human behavior... presents essentially the same kinds of problems as does the behavior of any other animal; and it must be studied by methods similar to, if not actually identical with, those emphasized by the student of infrahuman behavior" (Yerkes, quoted in Krasnogorski, 1925, p. 754). Today, Yerkes' assertion is supported by a plethora of data suggesting that the behavior of all organisms share common determinants and that methods used to investigate animal behavior are also relevant when studying human behavior. These similarities are illustrated by the three historical examples of animal model of psychopathologies that we discussed earlier.

Despite the generally unrecognized usefulness of animal research in psychological science, productivity in the area continues to be strong (see Benjumea \& Zentall, 2005, p. $130)$. Why has this type of research been ignored by mainstream psychology and applied scientists? We speculate there are at least two reasons for this. On the one hand animal researchers are often not effective at writing their results and theories in such a way as to make them relevant for the nonspecialist readers, and on the other hand psychologists from other areas do not pay enough attention to developments in basic research. At a time in which clinical researchers are seeking principles that have large effect sizes and mechanisms of change instead of trademark therapies (e.g., Lohr, DeMaio \& McGlynn, 2003; O’Donohue \& Yeater, 2003; Rosen \& Davison, 2003), improving communications between basic and applied researchers is indispensable. 
Importantly, the field of associative learning should be of special interest to clinical and experimental researchers interested in developing better treatments for behavioral disorders. As discussed earlier, the field of Pavlovian conditioning is not even remotely close to what it was in its early years. Currently, Pavlovian associations are thought to be involved in almost every behavioral interaction an organism has with its environment, helping animals to predict the regularities in their world. Moreover, the study of associations in non-human animals has discovered numerous phenomena that must be taking in count in clinical settings because they are often engaged in the etiology of psychopathological behaviors, and they may suggest potential treatments for them.

Alongside the specific Pavlovian phenomena that today are considered associative [mini] models of psychopathology, Pavlov's work left a permanent and profound effect on what is known today as behavior therapy. Thanks to Pavlov's pioneering work in experimental psychopathology, behavior therapy constitutes a psychotherapeutic approach that is based on testable theory and experimental studies, in which symptoms are provoked by dysfunctional associations that can be treated, thereby restoring normal behavior (Eysenck, 1988; Plaud, 2003). Considering that the Pavlovian approach to psychopathology and treatment presents a source of theories, methodologies, and findings that support behavioral-based psychotherapies, we concur with Plaud's (2001) assertion concerning the future of behavior therapy: "the future looks good for basic and applied behavior analysis as well as the practice of behavior therapy as long as advances in the behavioral laboratories are continually being integrated into clinical regimens" (p. 1100). If the goal is to keep developing effective psychotherapeutic treatments for behavioral disorders, then reinforcing the impaired relationship between basic findings in the Pavlovian laboratory and clinical applications is a must. "The work of Pavlov, therefore, far from being a thing of the past, will continue to be one of the major legacies for the future of behavior therapy" (Plaud, 2003, p. 153).

\section{References}

Abramson, L. Y., Metalsky, G., \& Alloy, L. B. (1989). Hopelessness depression: A theory-based subtype of depression. Psychological Review, 96, 358-372.

Abramson, L. Y., Seligman, M. E. P., \& Teasdale, J. (1978). Learned helplessness in humans. Critique and reformulation. Journal of Abnormal Psychology, 87, 49-74.

Anderson O. D., \& Liddell, H. S. (1935). Observations on experimental neurosis in sheep. Archive of Neurology and Psychiatry, 34, 330-354.

Balsam, P. D., \& Tomie, A. (1985). Context and learning. Hillsdale, NJ: Erlbaum.

Benjumea, S., \& Zentall. T. R. (2005). Darwin lives: Introduction to the series on animal learning and cognition. International Journal of Psychology and Psychological Therapy, 6, 129-132.

Betancourt, M., Inostroza, M., \& Laborda, M. A. (2008). Modulación contextual de la tolerancia asociativa al etanol. Revista Latinoamericana de Psicología, 40, 243-257.
Blaisdell, A. P., Gunther, L. M., \& Miller, R. R. (1999). Recovery from blocking by extinguishing the blocking stimulus. Animal Learning \& Behavior 27, 63-76.

Bouton, M. E. (1993). Context, time, and memory retrieval in the interference paradigm of Pavlovian learning. Psychological Bulletin, 114, 80-99.

Bouton, M. E. (2010). The multiple forms of "context" in associative learning theory. In B. Mesquita, L. F. Barrett, \& E. R. Smith (Eds.), The mind in context (pp. 233-258). New York, NY: Guilford Press.

Bouton, M. E., \& Bolles, R. C. (1979). Contextual control of the extinction of conditioned fear. Learning and Motivation, 10, 445-466.

Bouton, M. E., Mineka, S., \& Barlow, D. H. (2001). A modern learning theory perspective on the etiology of panic disorder. Psychological Review, 108, 4-32.

Bouton, M. E., \& Nelson, J. B. (1998). The role of context in classical conditioning: Some implications for cognitive behavior therapy. In W. O'Donohue (Ed.), Learning and behavior therapy (pp. 59-84). Boston, MA: Allyn and Bacon.

Bouton, M. E., \& Peck, C. A. (1992). Spontaneous recovery in crossmotivational transfer (counterconditioning). Animal Learning \& Behavior, 20, 313-321.

Bower, G. H., \& Hilgard, E. R. (1981). Theories of learning. Englewood Cliffs, NJ: Prentice-Hall.

Brogden, W. J. (1939). Sensory pre-conditioning. Journal of Experimental Psychology, 25, 323-332.

Brooks, D. C., Hale, B., Nelson, J. B., \& Bouton, M. E. (1995). Reinstatement after counterconditioning. Animal Learning \& Behavior, 23, 383-390.

Carey, T. A. (2011). Exposure and reorganization: The what and how of effective psychotherapy. Clinical Psychology Review, 31, 236-248.

Cason, H. (1922). The conditioned papillary reaction. Journal of Experimental Psychology, 5, 108-146.

Cason, H. (1925). The conditioned reflex or conditioned response as a common activity of living organisms. Psychological Bulletin, 22, 445-472.

Chambless, D. L., \& Ollendick, T. (2001). Empirically supported psychological interventions: Controversies and evidence. Annual Review of Psychology, 52, 685-716.

Coldwell. S. E., Wilhelm, F. H., Milgrom, P., Prall, C. W., Getz, T., Spadafora, A., et al., (2007). Combining alprazolam with systematic desensitization therapy for dental injection phobia. Journal of Anxiety Disorders, 21, 871-887.

Collins, B. N., \& Brandon, T. H. (2002). Effects of extinction context and retrieval cues on alcohol cue reactivity among nonalcoholic drinkers. Journal of Consulting and Clinical Psychology, 70, 390-397.

Cook, M., \& Mineka, S. (1990). Selective associations in the observational conditioning of fear in rhesus monkeys. Journal of Experimental Psychology: Animal Behavior Processes, 16, 372-389.

Cusato, B., \& Domjan, M. (1998). Special efficacy of sexual conditioned stimuli that include species typical cues: Test with a CS preexposure design. Learning and Motivation, 29, 152-167.

Darwin, C. (1859). The origin of the species. London, UK: J. Murray.

Darwin, C. (1872). Expression of emotions in man and animals. London, UK: J. Murray.

Davey, G. C. L. (1992). Classical conditioning and the acquisition of human fears and phobias: A review and synthesis of the literature. Advances in Behaviour Research and Therapy, 14, 29-66.

de Jong, P. J., Vorage, I., \& van den Hout, M. A. (2000). Counterconditioning in the treatment of spider phobia: Effect on disgust, fear and valence. Behaviour Research and Therapy, 38, 1055-1069.

Denniston, J. C., Chang, R. C., \& Miller, R. R. (2003). Massive extinction attenuates the renewal effect. Learning and Motivation, 34, 68-86.

Domjan, M. (2005). Pavlovian conditioning: A functional perspective. Annual Review of Psychology, 56, 179-206.

Domjan, M. (2010). The principles of learning and behavior. $6^{\text {th }}$ edition. Belmont, CA: Thomson/Wadsworth.

Domjan, M., \& Purdy, J. E. (1995). Animal research in psychology: More than meets the eye of the general psychology student. American Psychologist, 50, 496-503. 
Dorworth, T. R., \& Overmier, J. B. (1977). On learned helplessness: The therapeutic effects of electroconvulsive shock. Physiological Psycho$\log y, 4,355-358$.

Drummond, D. C., Tiffany, S. T., Glautier, S., \& Remington, B. (1995). Addictive behavior: Cue exposure theory and practice. West Sussex, England: John Wiley \& Sons Ltd.

Dwyer, D. M. (2003). Learning about cues in their absence: Evidence from flavour preferences and aversions. Quarterly Journal of Experimental Psychology, 56B, 56-67.

Eysenck, H. J. (1988). Psychotherapy to behavior therapy: A paradigm shift. In D. B. Fishman, F. Rotgers, \& C. M. Franks (Eds.), Paradigms in behavior therapy: Present and promise (pp. 45-76). New York, NY: Springer.

Fernández, V. M. (2000). Modelos animales en psicopatología. Elementos: Ciencia y Cultura, 6, 29-34.

Field, A. P. (2006). Is conditioning a useful framework for understanding the development and treatment of phobias? Clinical Psychology Review, $26,857-875$.

Gantt, W. H. (1944). Experimental basis for neurotic behavior: Origin and development of artificially produce disturbances of behavior in dogs. New York, NY: Paul B. Hoeber.

García-García, E. S., Rosa-Alcázar, A. I., \& Olivares-Olivares, P. J. (2011). Terapia de exposición mediante realidad virtual e internet en el trastorno de ansiedad/fobia social: Una revisión cualitativa. Terapia Psicológica, 29, 233-243.

Garcia, J., \& Koelling, R. A. (1966). Relation of cue to consequence in avoidance learning. Psychonomic Science, 4, 123-124.

Goodison, T., \& Siegel, S. (1995). Tolerance to naloxone-induced suppression of intake learning and cross-tolerance to cholecystokinin in rats. Behavioral Neuroscience, 109, 455-465.

Gunther, L. M., Denniston, J. C., \& Miller, R. R. (1998). Conducting exposure treatment in multiple contexts can prevent relapse. Behaviour Research and Therapy, 36, 75-91.

Gwinn, G. T. (1949). The effects of punishment on acts motivated by fear. Journal of Experimental Psychology, 39, 260-269.

Hofmann, S. G. (2008). Cognitive processes during fear acquisition and extinction in animals and humans: Implications for exposure therapy of anxiety disorders. Clinical Psychology Review, 28, 199-210.

Holland, P. C. (1983). "Occasion setting" in Pavlovian feature positive discrimnations. In M. L. Commons, R. J. Hernstein, \& A. R. Wagner (Eds.), Quantitative analyses of behavior: Volume 4. Discrimination processes (pp. 183-206). Cambridge, MA: Ballinger.

Hollis, K. L. (1997). Contemporary research on Pavlovian conditioning: A "new" functional analysis. American Psychologist, 52, 956-965.

Huesmann, L. R. (1978). Cognitive processes and models of depression. Journal of Abnormal Psychology, 87, 194-198.

Jones, M. C. (1924). The elimination of children's fears. Journal of Experimental Psychology, 7, 382-390.

Kamenetzky, G. V., \& Mustaca, A. E. (2004). Modelos animales para el estudio del alcoholismo. Terapia Psicológica, 23, 65-72.

Kamin, L. J. (1968). Attention-like processes in classical conditioning. In M. R. Jones (Ed.), Miami symposium on the prediction of behavior: Aversive stimuli (pp. 9-32). Coral Gables, FL: University f Miami Press.

Karasu, T. B. (1986). The psychotherapies: Benefits and limitations. American Journal of Psychotherapy, 40, 324-342.

Krasnogorsky, N. I. (1925). The conditioned reflexes and children's neuroses. American Journal of Diseases of Children, 30, 753-768.

Laborda, M. A. (2009). Modelos animales en psicopatología experimental: Miedo, tolerancia a las drogas y condicionamiento. Revista de Psicología, 18, 81-104.

Laborda, M. A., McConnell, B. L., \& Miller, R. R. (2011). Behavioral techniques to reduce relapse after exposure therapy: Applications of studies of experimental extinction. In T. R. Schachtman \& S. Reilly (Eds.), Associative learning and conditioning theory: Human and non-human applications (pp 79-103). New York, NY: Oxford University Press.

Laborda, M. A., \& Miller, R. R. (in press). Reactivated memories compete for expression after Pavlovian extinction. Behavioural Processes.
Laborda, M. A., \& Miller, R. R. (2011). S-R associations, their extinction, and recovery in an animal model of anxiety: A new associative account of phobias without recall of original trauma. Behavior Therapy, 42, 153-169.

Laborda, M. A., \& Miller, R. R. (2012). Preventing recovery from extinction in an animal model of anxiety: I. Additive effect of massive extinction and extinction in multiple contexts. Manuscript submitted for publication.

Laborda, M. A., Polack, C. W., \& Miller, R. R. (2012). Context-shift effects: Parallels between extinction and latent inhibition. Manuscript submitted for publication

Laborda, M. A., Witnauer, J. E., \& Miller, R. R. (2011). Contrasting $\mathrm{AAC}$ and $\mathrm{ABC}$ renewal: The role of context associations. Learning \& Behavior, 39, 46-56.

Lashley, K. S. (1916). The human salivary reflex and its use in psychology. Psychological Review, 23, 446-464.

Leaf, R. C. (1964). Avoidance response evocation as a function of prior discriminative fear conditioning under curare. Journal of Comparative and Physiological Psychology, 58, 446-449.

Leshner, A. I., Remler, H., Biegon, A., \& Samuel, D. (1979). Desmethylimipramine (DMI) counteracts learned helplessness in rats. Psychopharmacology, 66, 207-208.

Levis, D. J. (1991). A clinician's plea for a return to the development of nonhuman models of psychopathology: New clinical observations in need of laboratory study. In M. R. Denny (Ed.), Fear, avoidance, and phobias: A fundamental analysis (pp. 395-427). Hillsdale, NJ: Lawrence Erlbaum Associates.

Lohr, J. M., DeMaio, C., \& McGlynn, F. D. (2003). Specific and nonspecific treatment factors in the experimental analysis of behavioral treatment efficacy. Behavior Modification, 27, 322-368.

LoLordo, V. M. (2001). Learned helplessness and depression. In M. E. Carroll \& J. B. Overmier (Eds.), Animal research and human health: Advancing human welfare through behavioral science (pp. 63-77). Washington, DC: American Psychological Association.

Lubow, R. E. (1998). Latent inhibition and behavior pathology: Prophylactic and other possible effects of stimulus preexposure. In W. O'Donohue (Ed.), Learning and behavior therapy (pp. 107-121). Boston, MA: Allyn and Bacon.

Lubow, R. E., \& Moore, A. U. (1959). Latent inhibition: The effect of nonreinforced pre-exposure to the conditional stimulus. Journal of Comparative and Physiological Psychology, 52, 415-419.

Mackintosh, N. J. (1975). A theory of attention: Variations in the associability of stimuli with reinforcement. Psychological Review, 82, 276-298.

Masserman, J. H. (1943). Behavior and neurosis: An experimental psychoanalytic approach to psychobiologic principles. Chicago, IL: University of Chicago Press.

Matzel, L. D., Schachtman, T. R., \& Miller, R. R. (1985). Recovery of an overshadowed association achieved by extinction of the overshadowing stimulus. Learning and Motivation, 16, 398-412.

McDonald, R. V., \& Siegel, S. (2004). Intra-administration associations and withdrawal symptoms: Morphine-elicited morphine withdrawal. Experimental and Clinical Psychopharmacology, 12, 3-11.

Meadows, E., \& Zinbarg, R. (1991). Animal models of psychopathology: III. Treatment and prevention. Behavior Therapist, 14, 225-230.

Miller, R. R., \& Laborda, M. A. (2011). Preventing recovery from extinction and relapse: A product of current retrieval cues and memory strengths. Current Directions in Psychological Science, 20, 325-329.

Miller, R. R., \& Oberling, P. (1998). Analogies between occasion setting and Pavlovian conditioning. In N. A. Schmajuk \& P. C. Holland (Eds.), Occasion setting: Associative learning and cognition in animals (pp. 3-35). Washington, DC: American Psychological Association.

Mineka, S. (1985). Animal models of anxiety-based disorders: Their usefulness and limitations. In A. H. Tuma \& J. D. Maser (Eds.), Anxiety and the anxiety disorders (pp. 199-244). Hillsdale, NJ: Erlbaum.

Mineka, S., \& Kihlstrom, J. (1978). Unpredictable and uncontrollable aversive events: A new perspective on experimental neurosis. Journal of Abnormal Psychology, 87, 256-271.

Mineka, S., \& Sutton, J. (2006). Contemporary learning theory perspective on the etiology of fears and phobias. In M. G. Craske, D. Hermans, \& 
D. Vansteenwegen (Eds.), Fear and learning: From basic processes to clinical implications (pp. 75-97). Washington, DC: American Psychological Association.

Mineka, S., \& Zinbarg, R. (1991). Animal models of psychopathology. In C. E. Walker (Ed.), Clinical psychology: Historical and research foundations (pp. 51-86). New York, NY: Plenum Press.

Mineka S., \& Zinbarg, R. (2006). A contemporary learning theory perspective on anxiety disorders: It's not what you thought it was. American Psychologist, 61, 10-26.

Mustaca, A. E. (2004). Tratamientos psicológicos eficaces y ciencia básica. Revista Latinoamericana de Psicología, 26, 11-20.

Norambuena, X. A., Quintana, G. R., Ponce, E. H., \& Vogel, E. H. (2010). Asociaciones excitatorias entre el contexto y la consecuencia en la reinstalación de respuestas extinguidas en el aprendizaje causal humano Terapia Psicológica, 28, 55-67.

O’Donohue, W., \& Yeater, E. A. (2003). Individuating psychotherapies. Behavior Modification, 27, 313-321.

Ortiz, J., \& Vera-Villarroel, P. E. (2003). Investigaciones en psicología clínica basada en la evidencia en Chile: Un análisis bibliométrico de tres revistas de psicología. Terapia Psicológica, 21, 61-66.

Overmier, J. B. (2001). Del laboratorio a la clínica: Una parábola moderna. Revista Mexicana de Psicología, 18, 287-300.

Overmier, J. B. (2007). La investigación básica con animales fortalece la ciencia y práctica de la psicología. Interdisciplinaria, 24, 211-228.

Overmier, J. B., \& Burke, P. D. (1992). Animal models of human pathology: A bibliography of a quarter century of behavioral research, 1967-1992. Bibliographies in psychology, No. 12. Washington, DC: American Psychological Association.

Overmier, J. B., \& Leaf, R. C. (1965). Effects of discriminative Pavlovian fear conditioning upon previously or subsequently acquired avoidance responding. Journal of Comparative and Physiological Psychology, $60,213-217$.

Overmier, J. B., \& Seligman, M. E. P. (1967). Effects of inescapable shock upon subsequent escape and avoidance responding. Journal of Comparative and Physiological Psychology, 63, 28-33.

Paunovic, N. (2002). Prolonged exposure counterconditioning (PEC) as a treatment for chronic post-traumatic stress disorder and major depression in an adult survivor of repeated child sexual and physical abuse. Clinical Case Studies, 1, 148-169.

Paunovic, N. (2003). Prolonged exposure counterconditioning as a treatment for chronic posttraumatic stress disorder. Anxiety Disorders, 17, 479-499.

Pavlov, I. P. (1927). Conditioned reflexes (G.V. Anrep, Ed. \& Trans.). London, UK: Oxford University Press.

Pavlov, I. P. (1955). Selected works (J. Gibbons, Ed., S. Belsky, Trans.). Moscow: Foreign Languages Publishing House.

Pearce, J. M. (1987). A model for stimulus generalization in Pavlovian conditioning. Psychological Review, 94, 61-73.

Pearce, J. M., \& Bouton, M. E. (2001). Theories of associative learning in animals. Annual Review of Psychology, 52, 111-139.

Pearce, J. M., \& Hall, G. (1980). A model for Pavlovian learning: Variations in the effectiveness of conditioned but not of unconditioned stimuli. Psychological Review, 87, 532-552.

Peck, C. A., \& Bouton, M. E. (1990). Context and performance in aversive-to-appetitive and appetitive-to-aversive transfer. Learning and Motivation, 21, 1-31.

Pérez-Acosta, A. M. (2005). Fundamentos de las terapias de exposición contra las fobias: Una propuesta teórica integradora de la conducta de evitación. Terapia Psicológica, 23, 25-35.

Plaud, J. J. (2001). Clinical science and human behavior. Journal of Clinical Psychology, 57, 1089-1102.

Plaud, J. J. (2003). Pavlov and the foundation of behavior therapy. Spanish Journal of Psychology, 6, 147-154.

Powers, M. B., Halpern, J. M., Ferenschak, M. P., Gillihan, S. J., \& Foa, E. B. (2010). A meta-analytic review of prolonged exposure for posttraumatic stress disorder. Clinical Psychology Review, 30, 635-641.

Ramos, B., Siegel, S., \& Bueno, J. L. (2002). Occasion setting and drug tolerance. Integrative Physiological \& Behavioral Science, 37, 165-177.
Razran, G. (1961). The observable unconscious and the inferable conscious in current soviet psychophysiology: Interoceptive conditioning, semantic conditioning, and the orienting reflex. Psychological Review, $54,357-365$

Reed, A. L., Anderson, J. C., Bylund, D. B., Petty, F., El Refaey, H., \& Happe, H. K. (2009). Treatment with escitalopram but not desipramine decrease escape latency times in a learned helplessness model using juvenile rats. Psychopharmacology, 205, 249-259.

Reed, A. L., Happe, H. K., Petty, F., \& Bylund, D. B. (2008). Juvenile rats in the forced-swim test model the human response to antidepressant treatment for pediatric depression. Psychopharmacology, 197, 433-441.

Rescorla, R. A. (1973). The effect of US habituation following conditioning. Journal of Comparative and Physiological Psychology, 82, 137-143.

Rescorla, R. A. (1986). Extinction of facilitation. Journal of Experimental Psychology: Animal Behavior Processes, 12, 16-24.

Rescorla, R. A. (1988). Pavlovian conditioning: It's not what you think it is. American Psychologist, 43, 151-160.

Rescorla, R. A. (2003). Contemporary study of Pavlovian conditioning. Spanish Journal of Psychology, 6, 185-195.

Rescorla, R. A., \& Heth, C. D. (1975). Reinstatement of fear to an extinguished conditioned stimulus. Journal of Experimental Psychology: Animal Behavior Processes, 1, 88-96.

Rescorla, R. A., \& Wagner, A. R. (1972). A theory of Pavlovian conditioning: Variations in the effectiveness of reinforcement and nonreinforcement. In A. H. Black \& W. F. Prokasy (Eds.), Classical conditioning II: Current theory and research (pp. 64-99). New York, NY: Appleton-Century Crofts.

Richard, D. C. S., \& Lauterbach, D. L. (2006). Handbook of exposure therapies. New York, NY: Academic Press.

Rizley, R. C., \& Rescorla, R. A. (1972). Associations in second-order conditioning and sensory preconditioning. Journal of Comparative and Physiological Psychology, 81, 1-11.

Rosas, J. M., \& Bouton, M. E. (1998). Context change and retention interval can have additive, rather than interactive, effects after taste aversion extinction. Psychonomic Bulletin \& Review, 5, 79-83.

Rosen, G. M., \& Davison, G. C. (2003). Psychology should list empirically supported principles of change (ESPs) and not credential trademarked therapies or other treatment packages. Behavior Modification, 27, $300-312$.

Schmajuk, N. A., \& Holland, P. C. (1998). Occasion setting: Associative learning and cognition in animals. Washington, DC: American Psychological Association.

Seligman, M. E. P. (1975). Helplessness: On depression, development, and death. New York, NY: W. H. Freeman and Company.

Seligman, M. E. P., \& Maier, S. F. (1967). Failure to escape traumatic shock. Journal of Experimental Psychology, 74, 1-9.

Seligman, M. E. P., Maier, S. F., \& Geer, J. H (1968). Alleviation of learned helplessness in the dog. Journal of Abnormal Psychology, 73, 256-262.

Seligman, M. E. P., Maier, S. F., \& Solomon, R. L. (1971). Unpredictable and uncontrollable events. In F. R. Brush (Ed.), Aversive conditioning and learning (pp. 347-400). New York, NY: Academic Press.

Shettleworth, S. J. (1972). Constraints on learning. Advances in the Study of Behavior, 4, 1-68.

Shettleworth, S. J. (1994). Biological approaches to the study of learning. In N. J. Mackintosh (Ed.), Animal learning and cognition (pp. 185-219). San Diego, CA: Academic Press.

Skinner, B. F. (1938). The behavior of organisms: An experimental analysis. New York, NY: Appleton-Century Company.

Slifer, K. J., Eischen, S. E., \& Busby, S. (2002). Using counterconditioning to treat behavioural distress during subcutaneous injections in a paediatric rehabilitation patient. Brain Injury, 16, 901-916.

Stout, S. C., \& Miller, R. R. (2007). Sometimes-competing retrieval (SOCR): A formalization of the comparator hypothesis. Psychological Review, 114, 759-783.

Thompson, E. L. (1917). An analysis of the learning process in the snail, Physa Gyrina Say. Behavior Monographs, 3, 1-97. 
Thorndike, E. L. (1911). Animal intelligence: Experimental studies. New York, NY: Macmillan.

Twitmyer, E. B. (1902/1974). A study of the knee jerk. Journal of Experimental Psychology, 103, 1047-1066.

Urcelay, G. P., \& Miller, R. R. (2010). Two roles of the context in Pavlovian fear conditioning. Journal of Experimental Psychology: Animal Behavior Processes, 36, 268-280.

Valentine, G., Dow, A., Banasr, M., Pittman, B., \& Duman, R. (2008). Differential effects of chronic antidepressant treatment on shuttle box escape deficits induced by uncontrollable stress. Psychopharmacology, 200, 585-596.

Van Gucht, D., Baeyens, F., Vansteenwegen, D., Hermans, D., \& Beckers, T. (2010). Counterconditioning reduces cue-induced craving and actual cue-elicited consumption. Emotion, 10, 688-695.

Vera-Villarroel, P. E., \& Mustaca, A. E. (2006). Investigaciones en psicología clínica basada en la evidencia en Chile y Argentina. Revista Latinoamericana de Psicologia, 38, 551-565.

Wagner, A. R. (2003). Context-sensitive elemental theory. Quarterly Journal of Experimental Psychology, 56B, 7-29.

Wasserman, E. A., \& Miller, R. R. (1997). What's elementary about associative learning? Annual Review of Psychology, 48, 573-607.

Watson, J. B., \& Rayner, R. (1920). Conditioned emotional reactions. Journal of Experimental Psychology, 3, 1-14.
Wheeler, D. S., Chang, R. C., \& Miller, R. R. (2003). Massive preexposure and preexposure in multiple contexts attenuate the context specific of latent inhibition. Learning \& Behavior, 31, 378-386.

Williams, D. R., \& Williams, H. (1969). Automaintenance in the pigeon: Sustained pecking despite contingent non-reinforcement. Journal of the Experimental Analysis of Behavior, 12, 511-520.

Wolpe, J. (1952). Experimental neuroses as learned behavior. British Journal of Psychology, 43, 243-268.

Wolpe, J. (1954). Reciprocal inhibition as the main basis of psychotherapeutic effects. Archives of Neurology and Psychiatry, 72, 205-226.

Wolpe, J. (1958). Psychotherapy by reciprocal inhibition. Stanford, CA: Stanford University Press.

Wolpe, J. (1995). Reciprocal inhibition: Major agent of behavior change. In W. T. O'Donohue \& L. Krasner (Eds.), Theories of behavior therapy: Exploring behavior change (pp. 23-57). Washington, DC: American Psychological Association.

Yerkes, R. M., \& Morgulis, S. (1909). The method of Pawlow in animal psychology. Psychological Bulletin, 6, 257-273.

Zinbarg, R. (1990a). Animal models of psychopathology: I. Psychopathy. Behavior Therapist, 13, 235-239.

Zinbarg, R. (1990b). Animal research and behavior therapy Part I: Behavior therapy is not what you think it is. Behavior Therapist, 13, 171-175.

Zinbarg, R., \& Mineka, S. (1991). Animal models of psychopathology: II. Simple phobia. Behavior Therapist, 14, 61-65. 